\title{
COMPETÊNCIAS SOCIOLINGUÍSTICAS NA PROVA DO ENEM
}

\author{
Sammela Rejane de Jesus Andrade \\ Raquel Meister Ko. Freitag
}

\begin{abstract}
RESUMO
Diante da repercussão na mídia sobre o privilégio do tratamento de questóes de variação linguística na prova do Enem 2012, investigamos qual o peso deste conteúdo na prova de Linguagens, Códigos e suas Tecnologias do Enem no período de 2000 a 2012, considerando a abordagem dos contínuos de Bortoni-Ricardo (2004) e as diretrizes dos documentos norteadores.
\end{abstract}

PALAVRAS-CHAVE: variação linguística; Enem; sociolinguística.

\section{Introdução ${ }^{1}$}

1 o campo educacional, a Sociolinguística é área da Linguística cujas bases teóricas têm fomentado e permitido discutir realidades antes ignoradas, como a relação entre língua e sociedade e seu impacto na sala de aula, mas, principalmente, o mito da "língua homogênea". Resultados de estudos descritivos sociolinguísticos têm permitido o reconhecimento da diversidade de formas como variação linguística, partindo do princípio de que, em uma comunidade, coexistem formas distintas em diferentes contextos de uso.

Apesar de parecer natural a concepção da língua variável e heterogênea, ainda nos deparamos com estranhamentos por parte da mídia, que, em certa

1 Este texto apresenta recorte de trabalho desenvolvido no escopo do projeto "Impacto da Prova de Redação do Enem no currículo da rede pública estadual de Sergipe”, financiado pelo edital 13/2012 NAPEB FAPITEC (ANDRADE, 2014). 
medida, reflete o que pensa a sociedade, quando o Exame Nacional do Ensino Médio $\left(\right.$ Enem $\left.^{2}\right)$ apresenta questôes que consideram esse tema, mesmo que essas estejam totalmente aderentes ao que preconizam os documentos oficiais norteadores da avaliação, a exemplo dos Parâmetros Curriculares Nacionais de Língua Portuguesa (PCN) (BRASIL, 2000), edital de seleção de obras para o Programa Nacional do Livro Didático de Língua Portuguesa (PNLD) (BRASIL, 2012), e do próprio edital que regula o certame. Merece nosso destaque, para fins de reflexão do poder da mídia no que tange às questôes pedagógicas, a repercussão da prova da edição de 2012 do Enem: diversas matérias jornalísticas enfatizaram a presença de oito questóes (em um universo de 45), supostamente "idênticas", ou seja, que "cobravam o mesmo conteúdo", na prova de Linguagens, Códigos e suas Tecnologias. $\mathrm{O}$ artigo jornalístico intitulado "Enem faz a mesma pergunta oito vezes" 3 , publicado pelo jornal $O$ Globo logo após a realização do exame de 2012, enfatizou "uma preocupação excessiva em defender o uso oral e coloquial da língua", em detrimento da dita "língua padrão".

Este foi apenas mais um episódio da manifestação da mídia em torno da temática variação no contexto escolar. Em 2011, após a distribuição feita pelo Ministério da Educação (MEC) do livro didático "Por uma vida melhor", produzido pela Ação Educativa e escolhido pelo PNLD, destinado a alunos da Educação de Jovens e Adultos, muitos veículos das mais variadas mídias disseminaram informaçóes imprecisas e descontextualizadas, baseados em fra-

2 O Enem foi criado através da Portaria do Ministério da Educação no 438, de 28 de maio de 1998, com o objetivo de avaliar o desempenho do estudante ao fim da educaçáo básica, inicialmente visando contribuir com a melhoria da qualidade da educação pública. A partir de 2009, com a portaria $n^{\circ} 109$, de 27 de maio de 2009, este exame passou a ser utilizado também como mecanismo de seleçáo para o ingresso no ensino superior, além de funcionar como instrumento para o acesso a programas do governo federal, como o Programa Universidade para Todos, que foi criado pela Lei da Presidência da República, no 11.096/2005, cuja finalidade é a concessão de bolsas de estudos integrais e parciais a estudantes de cursos de graduação e de cursos sequenciais de formação específica, em instituiçóes privadas de educação superior. Em decorrência da instituição do Programa de Apoio a Planos de Reestruturação e Expansão das Universidades Federais, com o decreto no 6.096, de 24 de abril de 2007, as universidades federais começaram a aderir ao Novo Enem como método de seleçáo de candidatos para as vagas ofertadas, a fim de atender premissa de ampliação do acesso à educação superior, prevista como objetivo maior do programa.

3 Disponível em http://oglobo.globo.com/sociedade/educacao/vestibular/ Enem-faz-mesma-pergunta-oito-vezes-6679643, acessado em 30 mar 2015. 
ses isoladas retiradas do capítulo "Escrever é diferente de falar", voltado para apresentar ao estudante as diferenças entre a norma culta e as variantes com que ele convivia até chegar à escola. O caso repercutiu não só na mídia, mas em várias discussóes e publicaçóes acadêmicas na área da Linguística, mas sem o mesmo impacto e abrangência. ${ }^{4}$

Nestas "polêmicas" travadas entre a mídia e os conteúdos de cunho sociolinguístico, os maiores prejudicados são alunos e professores, que se veem diante da dúvida de pautar o ensino dentro dos parâmetros que indicam e norteiam uma educação para a formação cidadã ou de mecanismos e estratégias que garantam um melhor resultado em exames, na maioria das vezes se restringindo a esquemas "decorebas" em torno da nomenclatura da gramática normativa.

Em consonância a estudos que vêm se dedicando à análise da configuração da prova do Enem (FREITAG, 2014a; ALVES, 2014), e considerando que o Enem tem como função primeira auxiliar na elaboração de políticas públicas destinadas à última etapa da educação básica, é objetivo deste texto analisar como se dá a avaliação das competências linguísticas na prova de Linguagens, Códigos e suas Tecnologias, a fim de observar como são tratadas as teorias da língua e as descriçóes linguísticas, em especial, ao que concerne à variação linguística, averiguando se a versão propalada pela mídia se justifica empiricamente nos documentos oficiais.

\section{Orientaçóes do Enem para a prova de linguagens, códigos e suas tecnologias}

Na prova de Linguagens, Códigos e suas Tecnologias, o candidato deve apresentar conhecimentos associados a nove competências, que abrangem 30 habilidades, contidas na Matriz de Referência, além das cinco competências exigidas na prova de Redação. ${ }^{5}$

4 A questão pode ser conferida com mais detalhes em Baronas e Cox (2013), Cavalcanti (2013), Lucchesi (2011), entre outros.

5 A prova de Linguagens, Códigos e suas Tecnologias abrange quatro áreas do conhecimento: Língua Portuguesa, Língua Estrangeira Moderna, Educação Física, Arte e Tecnologia da Informação, e por esse motivo, para a discussão aqui proposta, serão observadas as habilidades e competências referentes apenas à Língua Portuguesa. 
Competência de área 1 - Aplicar as tecnologias da comunicação e da informação na escola, no trabalho e em outros contextos relevantes para sua vida.

Competência de área 2 - Conhecer e usar língua(s) estrangeira(s) moderna(s) como instrumento de acesso a informaçóes e a outras culturas e grupos sociais.

Competência de área 3 - Compreender e usar a linguagem corporal como relevante para a própria vida, integradora social e formadora da identidade.

Competência de área 4 - Compreender a arte como saber cultural e estético gerador de significação e integrador da organização do mundo e da própria identidade.

Competência de área 5 - Analisar, interpretar e aplicar recursos expressivos das linguagens, relacionando textos com seus contextos, mediante a natureza, função, organização e estrutura das manifestaçôes, de acordo com as condiçôes de produção e recepção. Competência de área 6 - Compreender e usar os sistemas simbólicos das diferentes linguagens como meios de organização cognitiva da realidade pela constituição de significados, expressão, comunicação e informação.

Competência de área 7 - Confrontar opinióes e pontos de vista sobre as diferentes linguagens e suas manifestaçôes específicas. Competência de área 8 - Compreender e usar a língua portuguesa como língua materna, geradora de significação e integradora da organização do mundo e da própria identidade. Competência de área 9 - Entender os princípios, a natureza, a função e o impacto das tecnologias da comunicação e da informação na sua vida pessoal e social, no desenvolvimento do conhecimento, associando-os aos conhecimentos científicos, às linguagens que lhes dão suporte, às demais tecnologias, aos processos de produçáo e aos problemas que se propóem solucionar. (BRASIL, 2009, p. 60)

Subjacentes às competências da Matriz de Referência há objetos de conhecimento associados que, em Língua Portuguesa, voltam-se, primordial- 
mente ao "estudo dos aspectos linguísticos da língua portuguesa: usos da língua: norma culta e variação linguística - uso dos recursos linguísticos em relação ao contexto em que o texto é constituído". (BRASIL, 2009, p. 62).

Entendendo que as competências da matriz da prova de Linguagens, Códigos e suas Tecnologias não se restringem à Língua Portuguesa, nosso foco volta-se às competências 5, 6, 7 e 8. Não ignorando as considerações que os documentos que norteiam a educação básica trazem, na medida em que o ensino nas escolas (pelo menos, na rede pública) segue essas diretrizes, que reverberam nos livros didáticos, sobre tipos textuais, os PCN (BRASIL, 2000, p. 8) apontam que se deve praticar "propostas que valorizam as variedades e pluralidade de uso linguístico, em diversos gêneros textuais orais e escritos, em todas as séries do ensino fundamental e médio". Vejamos como estas diretrizes se materializam na prova de Linguagens do Enem, especificamente no que tange à Língua Portuguesa.

\section{O tratamento da variaçáo linguística nas questóes da prova de linguagens do Enem}

A fim de observar como se dá abordagem da variação na prova do Enem, analisamos as questôes da prova de Linguagem, Códigos e suas Tecnologias das provas do período de 2000 a 2012 à luz do seguinte percurso metodológico: i) identificação da abordagem variacionista da questão, com o cotejamento quanto à aderência às proposiçóes dos contínuos de Bortoni-Ricardo (2004); ii) observação do gênero textual utilizado como enunciado de cada questão; iii) levantamento das terminologias utilizadas nas perguntas; iv) levantamento das terminologias utilizadas nas respostas. $\mathrm{O}$ cotejamento das proposiçôes contidas no exame e nos documentos norteadores permite traçarmos um panorama do tratamento da variação no exame, e paralelamente, podemos averiguar a fundamentação da polêmica midiática em torno do exame quanto à recorrência de questôes de variação linguística na prova do Enem.

\section{A variação linguística e os contínuos}

Para a análise das questóes, adotamos a proposta de contínuos de Bortoni-Ricardo (2004): o contínuo de urbanização, o de oralidade-letramento e o de monitoração estilística. 
O contínuo da urbanização é a proposição de uma linha imaginária, na qual em uma ponta se encontram os falares rurais mais isolados (com predomínio da cultura da oralidade) e, na outra, os falares urbanos (com predomínio da cultura de letramento), ambos com influências de codificação linguística, a exemplo do padrão da escrita; é preciso levar em consideração que esse tipo de influência ocorre com maior força nos falantes da zona urbana, devido à dificuldade de acesso dos falantes da zona rural. A figura 1 ilustra esse contínuo.

Figura 1. Contínuo da urbanização (BORTONI-RICARDO, 2004, p. 52)

\begin{tabular}{|lcr|}
\hline variedades & área & variedades urbanas \\
rurais isoladas & rurbana & padronizadas \\
\hline
\end{tabular}

Entre esses dois extremos (rural e urbano), encontra-se o que Bortoni-Ricardo (2004, p. 338) denomina de zona rurbana: "Denomino 'rurbanas', valendo-me da terminologia da antropologia social, comunidades urbanas de periferia, onde predomina forte influência rural na cultura e na língua”. Essa zona é composta pelos imigrantes da zona rural que preservam os seus antecedentes culturais, mas que sofrem forte influência através da mídia, por exemplo.

O sentido de propor as três zonas é evidenciar que não existem falares totalmente isolados, mas sim uma fluidez entre eles, como colocado por Bortoni-Ricardo (2004, p. 52): "No contínuo de urbanização, não existem fronteiras rígidas que separem os falares rurais, rurbanos ou urbanos. As fronteiras são fluidas e há muita sobreposição entre esses tipos de falares (por isso mesmo falamos de um contínuo)”.

O segundo contínuo proposto por Bortoni-Ricardo (2004) é o de oralidade-letramento, voltado para os eventos de comunicação mediados pela língua escrita. Também proposto em uma linha contínua, em um extremo, a autora coloca o que chama de eventos da oralidade, e no outro, eventos do letramento, que assim como o contínuo de urbanização, também é livre de fronteiras e marcado por sobreposiçóes (figura 2).

Figura 2. Contínuo da oralidade-letramento (BORTONI-RICARDO, 2004, p. 60)

eventos de

oralidade eventos

de letramento 
Sobre esse contínuo, Freitag e Cyranka (2014, p. 260) evidenciam que "diferentes situações em que recursos linguísticos próprios ora da fala, ora da escrita são utilizados marcando diferenças de estilo, de gênero textual, de modos de interação determinantes de variação linguística”. A diferença entre um evento de letramento e um de oralidade se dá pela presença de um roteiro escrito durante a fala, o que caracteriza um evento de letramento, já a ausência desse roteiro caracteriza o evento de fala.

Bortoni-Ricardo (2004) defende que o contato do indivíduo com o letramento escolar proporciona um maior domínio das variantes de prestígio, e consequentemente, o seu uso. Partindo do princípio de que o falante está a todo momento migrando entre situaçóes de oralidade e letramento, a participação em cada um dos polos do contínuo vai definir a sua predominância, uma vez que, como apontado por Bortoni-Ricardo (2004, p. 335), "nos diversos domínios sociais, inclusive na sala de aula, as atividades próprias da oralidade são conduzidas em variedades informais da língua, enquanto para as atividades de letramento os falantes reservam um linguajar mais cuidado”.

O último contínuo, o de monitoração estilística, divide-se em interação espontânea [- monitoração] e interação planejada [+ monitoração], conforme a figura 3, sendo três fatores que levam à monitoração do estilo: o ambiente, o interlocutor e o tópico da conversa.

Figura 3. Contínuo da monitoração estilística (BORTONI-RICARDO, 2004, p. 62)

- monitoração

+ monitoração

Fortemente correlacionado ao contínuo de urbanização, o contínuo de monitoramento linguístico apresenta os chamados traços graduais, uma vez que existe uma gradação à medida que um falante vai migrando do extremo esquerdo para o direito da linha contínua, ao apresentar um estilo mais monitorado.

À medida que os falantes se deslocam para o extremo direito desse contínuo, vão se tornando mais frequentes os chamados traços graduais, por se reconhecer neles uma gradação, desde 
as construções menos estigmatizadas, como o objeto direto lexical (Vi ele na rua), a oração adjetiva cortadora (O livro ø que gosto mais) até as mais formais, presentes em situaçóes de monitoração dos chamados falantes cultos. (FREITAG; CYRANKA, 2014, p. 260)

Bortoni-Ricardo (2004) aponta a importância de se levar em consideração o grau de atenção e de planejamento conferidos pelo falante na interação, decorrentes de fatores como: a acomodaçáo do falante ao seu interlocutor, o apoio contextual da produção dos seus enunciados, a complexidade cognitiva envolvida na sua produção linguística e a familiaridade do falante com a tarefa comunicativa que está sendo desenvolvida. E, ainda,

$\mathrm{Na}$ produção do estilo monitorado o/a falante presta mais atenção à sua fala. Este estilo geralmente caracteriza-se pela maior complexidade cognitiva do tema abordado. Se o/a falante tiver um maior grau de apoio contextual, bem como maior familiaridade com a tarefa comunicativa, poderá desempenharse no estilo monitorado com menor pressão comunicativa. A pressão comunicativa aumenta quando o apoio contextual é menor e a temática mais complexa. (BORTONI-RICARDO, 2004, p. 336).

As questóes da prova do Enem do período de 2000 a 2012 foram cotejadas, uma a uma, aos três contínuos, havendo, em alguns casos, a ocorrência de mais de um contínuo em uma mesma questão. Todavia, do universo de questôes que tratam de variação linguística identificadas no exame, nem todas se enquadraram na proposta de abordagem contínuos proposta pela autora; nesse caso, mesmo que em menor quantidade, também consideramos a ocorrência de outros fenômenos de variação presentes nessas questóes, como a variação regional no Brasil, a variação histórica e a variação entre o português brasileiro x português europeu. 
Figura 4. Questão no4 da prova de Linguagens, Códigos e suas Tecnologias. (Enem, 2006, p. 2)

\section{Questao 4}

Depois de um bom jantar: feijão com carne-seca, orelha de porco e couve com angu, arroz-mole engordurado, carne de vento assada no espeto, torresmo enxuto de toicinho da barriga, viradinho de milho verde e um prato de caldo de couve, jantar encerrado por um prato fundo de canjica com torrōes de açúcar, Nhô Tomé saboreou o café forte e se estendeu na rede. A mão direita sob a cabeça, à guisa de travesseiro, o indefectível cigarro de palha entre as pontas do indicador e do polegar, envernizados pela fumaça, de unhas encanoadas e longas, ficou-se de pança para o ar, modorrento, a olhar para as ripas do telhado.

Quem come e não deita, a comida não aproveita, pensava Nhô Tomé... E pôs-se a cochilar. A sua modorra durou pouco; Tia Policena, ao passar pela sala, bradou assombrada:

- Êêh! Sinhô! Vai drumi agora? Não! Num presta... Dá pisadêra e póde morrê de ataque de cabeça! Despois do armoço num far-má... mais despois da janta?!"

Cornélio Pires. Conversas ao pé do fogo. Săo Paulo: Imprensa Oficial do Estado de Săo Paulo, 1987.

O texto do enunciado da questáo de número 4 da prova amarela de Linguagens, Códigos e suas Tecnologias, edição de 2006, ilustrada na figura 4 , apresenta traços descontínuos do português, como em "Sinhô", "drumi", "morrê", "despois", entre outros, associados a um falante da zona rural, o que nos levou a classificar a questão como relacionada ao contínuo da urbanização. 
Figura 5. Questão no 99 da prova de Linguagens, Códigos e suas Tecnologias. (Enem, 2012, p. 6)

\section{QUESTÃO 99}

eu gostava muito de passeá... saí com as minhas colegas... brincá na porta di casa di vôlei... andá de patins... bicicleta... quando eu levava um tombo ou outro... eu era a:.... a palhaça da turma.., ((risos))... eu acho que foi uma das fases mais... assim... gostosas da minha vida foi... essa fase de quinze... dos meus treze aos dezessete anos...

A.P.S., sexo feminino, 38 anos, nível de ensino fundamental. Projeto Fala Goiana, UFG, 2010 (inédito).

Um aspecto da composição estrutural que caracteriza o relato pessoal de A.P.S. como modalidade falada da língua é

A predomínio de linguagem informal entrecortada por pausas.

B vocabulário regional desconhecido em outras variedades do português.

C realização do plural conforme as regras da tradição gramatical.

D ausência de elementos promotores de coesão entre os eventos narrados.

E presença de frases incompreensiveis a um leitor iniciante.

Na questão de número 99 da prova cinza do Enem de 2012, é apresentado o relato de uma mulher sobre as suas experiências vividas, como podemos ver na figura 5. O texto do enunciado da questão requer a habilidade de identificar um evento de oralidade, no contínu da oralidade/letramento, no qual a relatante não se apoia em nenhum roteiro para expor suas lembranças. Outra característica é o fato do seu grau de escolaridade ser identificado na questão, o que auxilia o leitor a tecer hipóteses sobre o grau de letramento da informante. 
Figura 6. Questão no 92 da prova azul de Linguagens, Códigos e suas Tecnologias. (Enem, 2009, p. 3)

\section{Questao 92}

Gerente - Boa tarde. Em que eu posso ajudá-lo?

Cliente - Estou interessado em financiamento para compra de veículo.

Gerente - Nós dispomos de várias modalidades de crédito. O senhor é nosso cliente?

Cliente - Sou Júlio César Fontoura, também sou funcionário do banco.

Gerente - Julinho, é você, cara? Aqui é a Helena! Cê tá em Brasília? Pensei que você inda tivesse na agência de Uberlândia! Passa aqui pra gente conversar com calma.

BORTONI-RICARDO, S. M. Educaçao em lingua materna. São Paulo: Parábola, 2004 (adaptado)

$\mathrm{Na}$ representação escrita da conversa telefônica entre a gerente do banco e o cliente, observa-se que a maneira de falar da gerente foi alterada de repente devido

( à adequação de sua fala à conversa com um amigo, caracterizada pela informalidade.

๑ à iniciativa do cliente em se apresentar como funcionário do banco.

C ao fato de ambos terem nascido em Uberlândia (Minas Gerais).

D à intimidade forçada pelo cliente ao fornecer seu nome completo.

G ao seu interesse profissional em financiar o veículo de Júlio.

Em um diálogo, a depender do contexto, do ambiente e do interlocutor, o falante vai produzir um estilo mais ou menos monitorado, como mostra a questão de número 92 da prova azul do Enem de 2009, na figura 6, em que, em uma conversa telefônica, o falante emprega um estilo mais monitorado ao atender um telefonema do banco onde trabalha como gerente; ao identificar que o solicitante é um conhecido, o estilo passa a ser menos monitorado e a tarefa comunicativa prossegue com a mudança de estilo. Tal questão ilustra o contínuo da monitoraçâo estilistica. 
No que se refere às questões nas quais os contínuos não se enquadraram, temos os exemplos em que foram detectados fenômenos de variação no nível mais diatópico, seja no território nacional, com falares regionais, seja em nível continental, com a oposição português europeu vs. português brasileiro, ou em nível diacrônico. O primeiro exemplo corresponde a uma abordagem de variação no contexto regional, em que o poema de Mário de Andrade é usado para tratar das diferenças linguísticas do falar em algumas regióes do país.

Figura 7. Questão no9 da prova amarela de Linguagens, Códigos e suas Tecnologias. (Enem, 2005, p. 5)

9

As dimensões continentais do Brasil são objeto de reflexões expressas em diferentes linguagens. Esse tema aparece no seguinte poema:

"(....)

Que importa que uns falem mole descansado

Que os cariocas arranhem os erres na garganta

Que os capixabas e paroaras escancarem as vogais?
Que tem se o quinhentos réis meridional

Vira cinco tostỗes do Rio pro Norte?

Junto formamos este assombro de misérias e grandezas,

Brasil, nome de vegetal! (....)"

(Mário de Andrade. Poesias completas. 6. ed. Săo Paulo: Martins Editora, 1980.)

O texto poético ora reproduzido trata das diferenças brasileiras no âmbito
(A) étnico e religioso.
(B) lingüistico e econômico.
(C) racial e folclórico.
(D) histórico e geográfico.
(E) literário e popular.

A respeito da variação regional, "o dialeto (ou variedade regional) falado em uma regiáo pobre pode vir a ser considerado um dialeto 'ruim', enquanto o dialeto falado em uma regiáo rica e poderosa passa a ser visto como um 'bom' dialeto" (BORTONI-RICARDO, 2004, p. 34). Nessa perspectiva, não podemos deixar de discutir o quão impregnada de estigmas é uma abordagem linguística regional, por carregar intrinsicamente a relação entre variedade de prestigio/variedade de estigma. Entretanto, a questão apenas leva o candidato a identificar de quais diferenças trata o texto, sem que haja um maior aprofundamento na temática.

Isso não é diferente do que é encontrado nas questôes de variação histórica, a exemplo da questâo de número 9 da edição de 2007, na qual um texto 
de Carlos Drummond de Andrade, produzido com o vocabulário contemporâneo ao período em que foi escrito, na década de 1960, é acompanhado de uma nova versão, na qual as palavras da "época passada” foram substituídas por palavras da "linguagem atual", nos termos do enunciado da questão.

Figura 8. Questão no 26 da prova amarela de Linguagens, Códigos e suas Tecnologias. (Enem, 2007, p. 9)

1 Ounst 26

\section{Antigamente}

Acontecia o individuo apanhar constipação; ficando perrengue, mandava o próprio chamar o doutor $e$, depois, ir à botica para aviar a receita, de cápsulas ou pilulas fedorentas. Doença nefasta era a phtísica, feia era - gálico. Antigamente, os sobrados tinham assombraçöes, os meninos, lombrigas (...)

Canos Drummond de Andrade. Poesla completa e proea. Fio de Janeiro: Companhia Jose Agurlar, p.1.18.4.

texto acima está escrito em linguagem de uma época passada. Observe uma outra versão, em linguagem atual.

\section{Antigamente}

Acontecia 0 individuo apanhar um resfriado; ficando mal, mandava o próprio chamar o doutor $e$, depois, ir à farmácia para aviar a receita, de cápsulas ou pilulas fedorentas. Doença nefasta era a tuberculose, feia era a sifilis. Antigamente, os sobrados tinham assombraçöes, os meninos, vermes (...)

Comparando-se esses dois textos, verifica-se que, na segunda versão, houve mudanças relativas a

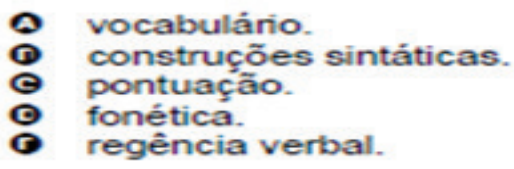

O léxico do português passou por várias mudanças ao longo do tempo, tendo em vista que a língua sofre constantemente processos de mudança, é natural que língua apresente alteraçôes no seu vocabulário. O processo histórico acarretou em muitas mudanças e fez do português brasileiro e do português europeu línguas carregadas de diferenças vocabulares, como aborda a questão 9 da prova amarela de 2005, na figura 9. 
Figura 9. Questão no6 da prova amarela de Linguagens, Códigos e suas Tecnologias. (Enem, 2005, p. 3)

Leia com atenção o texto:

[Em Portugal], você poderá ter alguns probleminhas se entrar numa loja de roupas desconhecendo certas sutilezas da língua. Por exemplo, nẫo adianta pedir para ver os ternos - peça para ver os fatos. Paletó é casaco. Meias são peúgas. Suéter é camisola - mas não se assuste, porque calcinhas femininas são cuecas. (Não é uma delicia?) (Ruy Castro. Viaje Bem. Ano VIII, n³,78.)

O texto destaca a diferença entre o português do Brasil e o de Portugal quanto
(A) ao vocabulário.
(B) à derivação.
(C) à pronúncia.
(D) ao gênero.
(E) à sintaxe.

A abordagem de variação linguística, nesta questão, se restringe aos itens lexicais, retomados na resposta como "vocabulário", sem fomentar uma discussão mais aprofundada a respeito do que caracteriza cada tipo de variação.

A seguir, discorremos sobre os mecanismos utilizados nos direcionamentos das questóes, a fim de averiguar de que maneira eles culminam nesse tipo de abordagem e como são aproveitados no âmbito das perguntas e respostas.

\section{Texto do enunciado das questões}

As questóes da prova do Enem, diferentemente dos exames vestibulares tradicionais, são caracterizadas por apresentarem enunciados mais extensos, contextualizados e explicativos. Para análise das questóes envolvendo variação linguística, é relevante observar o gênero textual envolvido nas questóes. $\mathrm{Na}$ definição de Marcuschi (2005, p. 30), "os gêneros não são entidades naturais como as borboletas, as pedras, os rios e as estrelas, mas são artefatos culturais construídos historicamente pelo ser humano". O gênero textual se caracteriza pela materialização dos textos em situaçóes comunicativas, variando de acordo com a sua funcionalidade; por conta disso, travam relação muito estreita com o fenômeno da variação linguística (cf. FREITAG, 2014b; FREITAG et alii, 2009, entre outros). 
Os PCN (BRASIL, 2000, p. 22) apontam que, em situação de ensino, o uso da língua materna depende da escolha de gêneros e tipos de discurso, e essas escolhas refletem no domínio de "contatos textuais" não declarados, mas que estão implícitos no texto. "Tais contatos exigem que se fale/escreva desta ou daquela forma, segundo este ou aquele gênero. Disso saem as formas textuais". A partir desta ótica, o uso dos gêneros textuais indica as possibilidades de usos da língua de acordo com o contexto.

Os conteúdos tradicionais do ensino de língua, ou seja, a nomenclatura gramatical e história da literatura, são deslocados para um segundo plano. $\mathrm{O}$ estudo da gramática passa a ser uma estratégia para compreensão/produção e interpretação de textos (...). A interaçáo é que faz com que a linguagem seja comunicativa. Esse princípio anula qualquer pressuposto que tenta referendar o estudo da língua isolada do ato interlocutivo. (BRASIL, 2000, p. 18)

Por serem a forma como a língua se organiza para se manifestar nas mais diversas situações de comunicação, os gêneros textuais apresentam seu próprio estilo e estrutura, possibilitando, assim, que sejam identificados através de suas características. A abordagem de um gênero específico no enunciado de uma questão vai conduzir a interpretação da variação linguística: se será o romance, o artigo acadêmico, o conto e a receita culinária, que são gêneros escritos, ou ainda textos orais como a aula, o debate, a palestra, entre outros. E, mais importante que isso, os gêneros possibilitam identificar o contexto que retratam, como evidenciado na habilidade de número 25 da matriz do Enem - Identificar, em textos de diferentes gêneros, as marcas linguísticas que singularizam as variedades linguísticas sociais, regionais e de registro. 
Figura 10. Questão no 14 da prova azul de Linguagens, Códigos e suas Tecnologias. (Enem, 2008, p. 6)
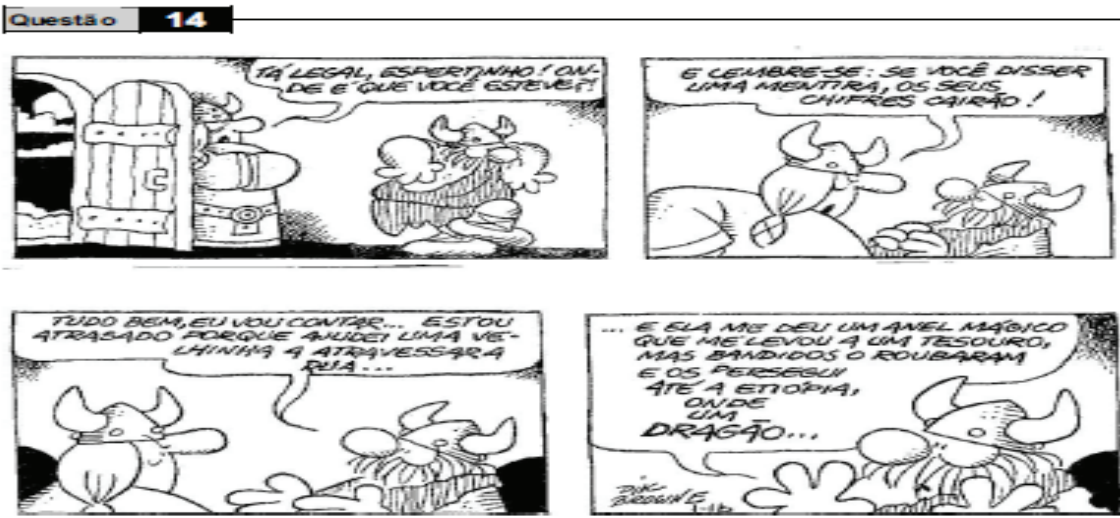

Dick Browne. O melhor de Hagar, o hornivel, v. 2. L.8.PM pocket, p.55-6 (com adaptagoes).

Assinale o trecho do diálogo que apresenta um registro informal, ou coloquial, da linguagem.

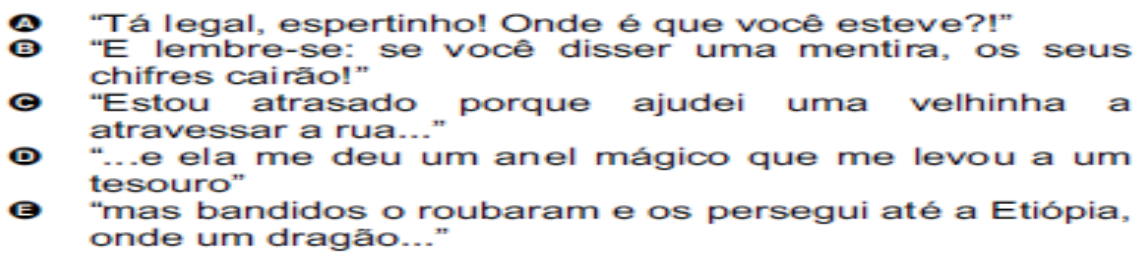

As histórias em quadrinhos, por se tratar de um gênero textual de comunicação visual e elementos verbais que retratam uma narrativa, têm como predominância do registro oral. No caso do quadrinho de Hagar, na questão 14 da prova do Enem de 2008, reproduzida na figura 10, o diálogo acontece entre marido e mulher e tem como tema um assunto corriqueiro entre cônjuges: a indagação da esposa a respeito da saída do marido. A contextualização do gênero textual utilizado, do enredo e das personagens é, nessa situação, favorável para discussão em torno da variação linguística no que diz respeito à informalidade e ao uso coloquial, uma vez que, através dos elementos que compóem a questão, sejam eles implícitos ou explícitos, é possível tratar da variabilidade da língua de acordo com os contextos de uso.

A observação do gênero textual utilizado nos enunciados das questóes em correlação com contínuos de Bortoni-Ricardo (2004) possibilita a identi- 
ficação de uma tendência no exame. Quando os gêneros textuais utilizados são de base mais informal, mais voltados para a oralidade, a exemplo das histórias em quadrinho, canção, charge e relato pessoal, existe uma forte ocorrência do contínuo de oralidade-letramento, caracterizado como eventos de comunicação mediados ou não pela língua escrita. Já quando os gêneros textuais tendem à formalidade, como o poema, conto, artigo de opinião e artigo acadêmico, há a prevalência do contínuo de monitoração estilística, relacionado ao grau de atenção e de planejamento conferidos pelo falante. E, por fim, o contínuo de urbanização ocorre em gêneros tanto mais formais, quanto informais.

\section{Objeto da pergunta e das alternativas}

Ao analisar o objeto das perguntas e das alternativas, observamos as terminologias linguísticas utilizadas para a indagação e as alternativas de respostas de cada questão. Predomina uma diversidade de terminologias, como for$\mathrm{mal} /$ informal, modalidade falada/escrita, variedade padrão/popular, e muitas outras.

Uma vez que o uso da língua atende às demandas sociais, a oralidade e a escrita se caracterizam como práticas e usos específicos da língua, haja vista que apresentam condições de produção distintas. Para os PCN (BRASIL, 2000 , p. 22), o aluno deve fazer escolhas conscientes no que tange à fala/escrita, e isso é possível através de um olhar crítico sobre o texto, refletindo sobre as marcas de atualização da linguagem "posição dos interlocutores, o contexto extraverbal, suas normas, de acordo com as expectativas em jogo, as escolhas dos gêneros e recursos".

Assim como nos gêneros textuais, a perspectiva do oral/escrito auxilia na construção dos questionamentos das perguntas sobre variação linguística na prova do Enem; as terminologias utilizadas partem dessa perspectiva para nortear as habilidades requeridas para resolução das indagaçóes feitas nas questóes, a exemplo da questão da figura 11. 
Figura 11. Questão no 125 da prova azul de Linguagens, Códigos e suas Tecnologias. (Enem, 2009, p. 14)

\section{Questros 120}

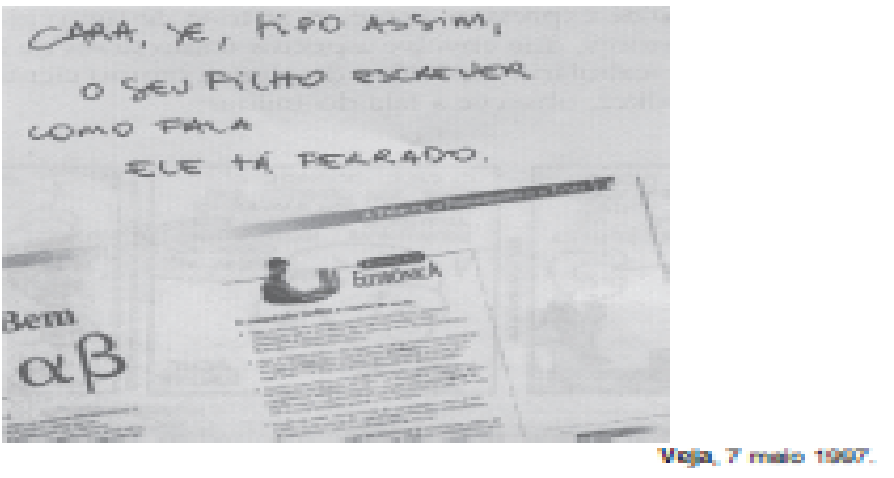

Na parte superior do anúncio, há um comentário escrito à mäo que aborda a questäo das atividades linguísticas e sua relagáo con as modalidades oral e escrita da língua. Esse con̉nentário deixa evidente unna posigäo critica quanto a usos que se fazem da linguagenn, enfatizando ser necessário

Q implementar a fala, tendo enn vista maior desemvoltura, maturalidade e segurança no uso da língua -

Q conhecer gêneros maís fomais da modalidade oral para a obtenģo de clareza na comumicagáo oral e escrita.

Q dominar as diferentes variedades do registro oral da língua portuguesa para escrever com adequacäo. eficibncia e comegäo.

(c) empregar vocabulário adequado e usar regras da noma padräo da língua em se tratando da nodalidade escrita.

9 utilizar necursos mais expressivos e menos desgastados da variedade padráo da língua para se expressar com alguma seguranga e sucesso.

Com foco na abordagem oral/escrito, a questão de número 125 traz o gênero anúncio como plano secundário na discussão, dirigindo o questionamento para o comentário escrito à mão na parte superior do texto, que tem como locutor alguém que chama atenção para o fato de que não se deve escrever como se fala; todavia, para expressar seu posicionamento, o próprio locutor carrega de gírias e palavras prototípicas da oralidade, propagando, assim, o discurso geral e discriminatório quanto ao uso da modalidade oral e escrita, já que defende um posicionamento e não o pratica. 
No que se refere às terminologias, o objeto da pergunta se fundamenta a partir da relação "modalidade oral e escrita da língua", indicando a variação a partir dos usos da língua. Quanto ao objeto das alternativas, as terminologias utilizadas são: fala, comunicação oral e escrita, registro oral, norma padrão e variedade padrão, sendo a resposta que o candidato deveria marcar, segundo o gabarito oficial, é a alternativa $\mathrm{D}$, que reporta ao uso da norma padrão para a constituição da modalidade escrita. Mesmo se tratando de uma questáo de variação, o enfoque culminou na prescrição normativa, sem maiores induçôes a respeito dos contextos de uso, fato observado na maioria das questóes do exame, que se mantiveram dentro desse contexto restritivo.

\section{Balanço final}

A análise da concepção de língua contida nos documentos norteadores e a avaliação de como essa se materializa em exames pilares para constituição de políticas públicas para o ensino da Língua Portuguesa, no caso o Enem, evidenciou a abordagem sociolinguística da língua. Quanto à prova de Linguagem, Códigos e suas Tecnologias, o levantamento das questóes de variação linguística evidenciou a implementação das prescriçóes contidas nos documentos, identificada desde a presença das concepçóes sociolinguísticas dos contínuos propostos por Bortoni-Ricardo (2004), até a existência das terminologias indicativas de variação, demonstrando que há uma congruência de abordagens.

Todavia, o êxito ainda não é o esperado devido à necessidade de uma abordagem menos velada e implícita de questóes normativas no exame, como foi constatado nas terminologias entre perguntas e respostas das questóes analisadas, que tendem a levar o candidato a responder sobre fatos em torno da gramática tradicional ainda atrelados à supremacia de uma dada variante. Esse tipo de abordagem resulta da competência primeira do exame "o domínio da norma culta", quanto à concepção de norma adotada pelo exame, como observado por Faraco:

Nossa crítica é que há na definição dessa grande competência dois equívocos. O primeiro é não distinguir suficientemente a norma culta da norma curta (o que leva os documentos do exame a falarem em norma culta e as questóes a se orientarem antes pelos preceitos de norma curta). Segundo e mais sério, tomar 
a norma como um fenômeno em si, isolado das práticas sociais de fala e escrita em que ela faz sentido e, por consequência, sobrepondo-se a elas. (FARACO, 2008, p. 179).

No entanto não podemos deixar de evidenciar que a metodologia adotada no Enem já há algum tempo passa a induzir mudanças na prática escolar, essas esperadas desde a reforma das diretrizes curriculares na década de 90 , uma vez que já demonstra grandes avanços na perspectiva de prevalência normativa, como vista nos tradicionais exames vestibulares.

A temática da variação linguística vem sendo tratada na avaliação, reflexo das orientaçóes dos documentos norteadores, se materializando em torno de situaçôes reais de comunicação por intermédio de recursos textuais, a exemplo das histórias em quadrinhos e dos diálogos, abordando a oralidade e informalidade da língua.

Como vimos, a mídia brasileira tem se mostrado implacável quando o assunto é o entendimento da língua como variável e heterogênea. Toda a discussão que foi levantada no presente trabalho, respaldada pelos documentos norteadores das políticas públicas educacionais e pela análise do exame de maior relevância atual no país, confronta a existência desse tipo de concepção ainda hoje. Haja vista a quantidade de informações esclarecedoras já existentes sobre o assunto, não cabem mais opiniōes descontextualizadas com a nova demanda para o ensino de Língua Portuguesa.

Ver uma mídia que estranha questóes de variação em exames e o tratamento das mesmas em livros didáticos configura que ainda existe a defesa da supremacia de uma língua "pura", pautada no ensino da gramática pela gramática, talvez corroborada pelas práticas ainda existentes nas salas de aula, no livro didático, entre outros.

A polêmica em torno das questóes "repetidas" em 2012, só reverbera que o foco que foi dado ao assunto tem qualquer alicerce, menos o educacional. Para discutir ensino de Língua Portuguesa é primordial considerar o que o fundamenta: os Parâmetros Curriculares, o Livro Didático e a Matriz do Enem, documentos de fácil acesso e já discutidos a exaustão por diversas investigaçóes acadêmicas. Nesses, todas as orientações levam para o entendimento da língua como instrumento de comunicação e interação dos agentes participativos da sociedade, ou seja, intrinsicamente associadas à variação. Sendo assim, nada 
mais natural do que as questóes relacionadas à variação linguística e ao preconceito linguístico estejam presentes, seja nos livros didáticos, no Enem ou em qualquer outro exame, com a devida ocorrência e representativa que deve ter.

\section{Referências}

ALVES, Rosana Ferreira. Caracterização de questôes de gramática no Enem. Cadernos do CNFL, v. XVIII, n. 12, p. 176-196, 2014.

ANDRADE, Sammela Rejane de Jesus. Competências linguisticas na prova do Enem: uma abordagem sociolinguística. Dissertaçâo (Mestrado em Letras). Universidade Federal de Sergipe, 2014.

BARONAS, Roberto Leiser; COX, Maria I. Pagliarini. Por uma vida melhor na midia: discurso, aforização e polêmica. In: Linguagem em (Dis)curso. Tubarâo, SC, v. 13, n. 1, p. 65-93, jan/abr, 2013.

BORTONI-RICARDO, Stella Maris. Educação em língua materna: a sociolinguística na sala de aula. São Paulo: Parábola, 2004.

BRASIL. Ministério da Educação. Instituto Nacional de Estudos e Pesquisas Educacionais Anísio Teixeira - INEP. Portaria no 109, de 27 de maio de 2009.

Ministério da Educação. Instituto Nacional de Estudos e Pesquisas Educacionais Anísio Teixeira - INEP. Provas e Gabaritos. Acesso em 08/11/2015.

- Ministério da Educação. Secretaria da Educação Média e Tecnológica. Guia do livro didático PNLD. Brasília: Ministério da Educação, 2012.

. Ministério da Educação. Secretaria de Educação Média e Tecnológica. Parâmetros Curriculares Nacionais (Ensino Médio). Brasília: MEC, 2000.

CAVALCANTI, Januarice Rodrigues As faces de uma polêmica: o episódio do livro didático Por uma vida melhor. Delta, v. 19, n. esp. p. 485-501, 2013.

Enem faz a mesma pergunta oito vezes. Disponível em: http://oglobo.globo. $\mathrm{com} /$ sociedade/educacao/vestibular/enem-faz-mesma-pergunta-oito-vezes-6679643. Acesso em: 06 de janeiro de 2015.

FARACO, Carlos Alberto. Norma culta Brasileira: desatando alguns nós. São Paulo: Parábola, 2008.

FREITAG, Raquel Meister Ko. A prova de redação do Enem: divergências entre as orientaçóes para a prática e as diretrizes de avaliação. Interdisciplinar: Revista de Estudos em Lingua e Literatura, v. 20, p. 61-72, 2014 a. 
FREITAG, Raquel Meister Ko. Dissecando a entrevista sociolinguística: estilo, sequência discursiva e tópico. In: GORSKI, Edair Maria; COELHO, Izete Lehmkuhl; SOUZA, Christiane Maria Nunes de (Orgs.). Variação estilística: reflexões teórico-metodológicas e propostas de análise. Florianópolis: Insular, 2014 b, p. 125-141.

. et alii. O controle do gênero textual/sequências discursivas na motivação da variação linguística: apontamentos metodológicos. Odisseia, v. 3, p. 5, 2009.

. CYRANKA, Lúcia Mendonça. Sociolinguística variacionista e educacional: tendências metodológicas. In: GONÇALVES, Adair Vieira; GÓIS, Márcio Lúcio (Org.). Ciências da linguagem: o fazer científico, v. 2, p. 249280, 2014.

LUCCHESI, Dante. Ciência ou dogma? O caso do livro do MEC e o ensino de língua portuguesa no Brasil. Revista Letras, v. 83, p. 163-187, 2011.

MARCUSCHI, Luiz Antônio. Gêneros textuais: definição e funcionalidade. In: DIONÍSIO, Angela Paiva; MACHADO, Anna Rachel; BEZERRA, Maria Auxiliadora. (Org.). Gêneros textuais e ensino. 4. ed. Rio de Janeiro: Lucerna, 2005.

\title{
SOCIOLINGUISTICS SKILLS IN ENEM ASSESSMENT
}

\begin{abstract}
Before media impact on the prevalence of questions of linguistic variation in Enem assessment in 2012, we provide an investigation about the weight of this content in the Language, Codes and Technologies test between 2000 and 2012 editions of Enem assessments. In the analysis, we consider Bortoni-Ricardo's (2004) continua approach and the guidelines of official documents.
\end{abstract}

KEYWORDS: linguistic variation; Enem assessment, sociolinguistics.

Recebido em: 31/03/2015

Aprovado em: 26/09/2015 